The following text is a pre-print (i.e. pre-refereeing) version of the article which differs from the publisher's version.
Restrictions: 24 months embargo

\title{
Prediction of static and low-cycle durability of porous cellular structures with positive and
}

\section{negative Poisson's ratios}

\author{
Dejan Tomažinčíci ${ }^{1, *}$, Matej Vesenjak ${ }^{2}$, Jernej Klemenc ${ }^{1}$ \\ ${ }^{1}$ University of Ljubljana, Faculty of Mechanical Engineering, Aškerčeva 6, 1000 Ljubljana, Slovenia \\ ${ }^{2}$ University of Maribor, Faculty of Mechanical Engineering, Smetanova 17, 2000 Maribor, Slovenia
}

\begin{abstract}
The static and low-cycle durability of three planar cellular structures, hexagonal, auxetic and auxetic-chiral, have been compared. The three structures have the same critical cross-section and are made from an aluminium alloy Al7075-T651. The reference region of each structure is represented by a matrix of nine elementary shaped cells (3 rows by 3 columns). For each structure static and low-cycle fatigue experiments at different loading amplitudes were made. Numerical simulations were then performed for the same boundary conditions to predict the static and low-cycle fatigue durability. For this purpose a continuum damage mechanics approach with element removal was used in explicit dynamic simulations. The results of static simulations were also checked using the eXtended Finite Element Method (XFEM). All the numerical simulations were carried out using Abaqus. Good agreement was observed between the simulated and measured results for each of the three cellular structures.
\end{abstract}

\section{Key words}

Low-cycle fatigue; Element removal; XFEM; Aluminium alloy; Auxetic; Honeycomb; Strain-energy density

This article should be cited as: D. Tomažinčič, M. Vesenjak, J. Klemenc, Prediction of static and low-cycle durability of porous cellular structures with positive and negative Poisson's ratios. Theor. Appl. Fract. Mech. 106 (2020) 102479. https://doi.org/10.1016/j.tafmec.2020.102479

\footnotetext{
* Corresponding author.

E-mail address: dejan.tomazincic@ @fs.uni-lj.si (D. Tomažinčič).
} 


\section{Nomenclature}

\begin{tabular}{|c|c|c|}
\hline$b$ & {$[-]$} & Fatigue strength exponent \\
\hline$c$ & {$[-]$} & Fatigue ductility exponent \\
\hline$d_{i}$ & {$[-]$} & Individual damage variable \\
\hline$l_{0}$ & {$[\mathrm{~mm}]$} & Reference length \\
\hline$n$ ' & {$[-]$} & Cyclic strain hardening exponent \\
\hline$p$ & {$[-]$} & Porosity \\
\hline$t$ & {$[\mathrm{~mm}]$} & Specimen thickness \\
\hline $\bar{u}_{f}^{p l}$ & {$[\mathrm{~mm}]$} & Plastic displacement at failure \\
\hline$A$ & {$\left[\mathrm{~mm}^{2}\right]$} & Cross-section \\
\hline$D$ & {$[-]$} & Damage variable \\
\hline$E$ & {$[\mathrm{MPa}]$} & Young's modulus \\
\hline$G_{f}$ & {$[\mathrm{~N} / \mathrm{mm}]$} & Fracture energy dissipation \\
\hline$K^{\prime}$ & {$[\mathrm{MPa}]$} & Cyclic strain hardening coefficient \\
\hline$L_{c h}$ & {$[\mathrm{~mm}]$} & Characteristic length of the finite element \\
\hline$N$ & {$[-]$} & Number of cycles to crack initiation \\
\hline$R$ & {$[-]$} & Stress ratio \\
\hline$\varepsilon$ & {$[-]$} & Strain \\
\hline$\dot{\varepsilon}$ & {$[-]$} & Strain rate \\
\hline$\varepsilon_{a}$ & {$[-]$} & Strain amplitude \\
\hline$\varepsilon_{f}^{\prime}$ & {$[-]$} & Fatigue ductility coefficient \\
\hline $\bar{\varepsilon}_{f}^{p l}$ & {$[-]$} & Fracture strain \\
\hline$\varepsilon_{p}$ & {$[-]$} & Plastic strain \\
\hline$\eta$ & {$[-]$} & Stress triaxiality factor \\
\hline$v$ & {$[-]$} & Poisson's ratio \\
\hline$\rho$ & {$\left[\mathrm{g} / \mathrm{cm}^{3}\right]$} & Density \\
\hline$\sigma$ & {$[\mathrm{MPa}]$} & Stress \\
\hline$\sigma_{1,2,3}$ & {$[\mathrm{MPa}]$} & Principal stresses \\
\hline $\bar{\sigma}$ & {$[\mathrm{MPa}]$} & Stress due to undamaged response \\
\hline$\sigma_{f}^{\prime}$ & {$[\mathrm{MPa}]$} & Fatigue strength coefficient \\
\hline$\sigma_{m}$ & {$[\mathrm{MPa}]$} & Mean stress in the cycle \\
\hline$\sigma_{\max }$ & {$[\mathrm{MPa}]$} & Maximum stress in the cycle \\
\hline$\sigma_{u}$ & {$[\mathrm{MPa}]$} & Ultimate strength \\
\hline$\sigma_{y}$ & {$[\mathrm{MPa}]$} & Yield strength \\
\hline$\kappa_{t}$ & {$[-]$} & Surface finish factor \\
\hline$\Delta l$ & {$[\mathrm{~mm}]$} & Length change \\
\hline$\Delta \varepsilon$ & {$[-]$} & Strain range for the cycle \\
\hline$\Delta \varepsilon_{n}$ & {$[-]$} & Normal strain \\
\hline$\Delta \gamma$ & {$[-]$} & Shear strain \\
\hline
\end{tabular}




\section{Introduction}

Nowadays it is not enough for a light-weight design to simply optimise the shape in order to reduce the mass of components and products. For this reason cellular structures are used not only in the aerospace engineering, but also in the automotive industry to significantly reduce the mass of transport equipment. However, the mass reduction should not lead to a significant reduction in the load-carrying capacity of a structure. If cellular structures are properly designed using elementary cell geometries, the mechanical properties of the overall structure of a component or product can be significantly improved.

Three structures with potential for such lightweight components are auxetic, auxetic-chiral and hexagonal structures. Auxetic structures have a negative Poisson's ratio [1-3] and since most structures today are loaded with variable loads, the auxetic structures should also have sufficient fatigue resistance to withstand repetitive loading. Basic research on lowcycle fatigue of a classic auxetic structure (Fig. 1-B) was carried out by Tomažinčič et al. [4]. It was previously proven that this kind of structure has a negative Poisson's ratio [5] and acceptable fatigue strength [6], but by changing the geometry the mechanical properties can be further improved. This classic auxetic structure has straight links between the structural nodes. As a consequence the structure is relatively rigid since most of the rotations during in-plane tensilecompressive loading occur at the nodes. To enable bending of the structural links between the nodes, the auxetic structure can be modified into a chiral shape (Fig. 1-A). Increased flexibility of the auxetic-chiral structure is achieved by using curved links between the structural nodes. During tensile-compressive loading, bending of the links occurs which improves structural flexibility.

Fig. 1. Geometries and static failures of the planar cellular structures studied in this paper: (A) auxetic-chiral

\section{structure, (B) classic auxetic structure, (C) hexagonal honeycomb structure}

Hexagonal honeycomb structures also offer the possibility of lightweight components with improved mechanical properties (Fig. 1-C). Such structures can often be found in biological structures, e.g. beehives, clusters of soap bubbles. Due to its geometric advantages, honeycomb structures are applied in many advanced cutting-edge structural elements. One such interesting application of hexagonal shapes is in the coverplate surface of combat-aircraft fuselages to improve stealth properties [7].

Little fatigue-life data is available for classic- and chiral-auxetic structures [8] and the fatigue-life data of honeycomb structures are mostly available for composite structures with honeycomb cores $[9,10]$. For this reason a comparison between the low-cycle fatigue properties of the three above-mentioned planar cellular structures has been carried out here. 
All three structures were cut from a $2 \mathrm{~mm}$ thick rolled plate of aluminium alloy $7075-\mathrm{T} 651$. It is a $\mathrm{Al}-\mathrm{Zn}-\mathrm{Mg}-\mathrm{Cu}$ alloy that was tempered and artificially aged. High-grade 7xxx aluminium alloy was selected because its material properties are known [11-13]. Furthermore its strength is similar to some low-alloy steels, which makes it a suitable candidate to replace steel in light-weight design applications. As can be seen in Fig. 1 the basic specimen geometries were designed in such a manner that the nominal cross-sections of the material in the middle of the specimen are equal for all three cellular structures. The central matrix of nine cells ( 3 rows by 3 columns), for which links are all of equal width, is connected to the specimen ends via a transition zone with the same pattern of cells, but with increasing link widths (Fig. 1). The same specimen geometry was used for static and low-cycle fatigue experiments. The static tensile test served as a basis for selecting the amplitude displacements of full reversal $\left(R_{\varepsilon}=-1\right)$ low-cycle fatigue experiments. Since the specimens were dynamically loaded in the elastic-plastic domain, a special guidance device was applied to prevent out-of-plane buckling of specimens during the compressive loading phase (Fig. 2).

\section{Fig. 2. Experimental arrangement for static and dynamic testing of the planar cellular structures}

To design cellular structural elements one should be able to predict their durability in the early phases of research and development $(R \& D)$. Finite element codes are usually used for estimating the durability of structural components. Hence durability analyses for the tensile- and low-cycle fatigue tests were also carried out using the commercial finite element codes Abaqus and SIMULIA fe-safe. Finite element models were built for each cellular shape and known material parameters of the Al7075-T651 alloy used [4]. For the first time, the technique of finite element removal within explicit dynamic simulations was combined with an energy-based continuum damage mechanic approach (CDM) for cellular structures with negative Poisson's ratios. The additional parameters required for the CDM approach were calculated from previous tensile test results of standardised Al7075-T651 specimens [4]. Crack initiation during the simulation of a tensile test was checked using an alternative technique, the eXtended Finite Element Method (XFEM). The results of all numerical simulations were compared to the experimental results.

The structure of the article is as follows. After the introductory section, the experiments and their results are presented. Next, a description of the applied finite-element models is given with particular attention given to the determination of the material parameters for the CDM approach, which is followed by a presentation of the simulated results and a discussion. The article ends with a concluding section, acknowledgements and a list of references. 


\section{Experimental methods}

\subsection{Tensile tests}

Tensile tests of the classic auxetic structure have already been presented in depth by Tomažinčič et al. [4]. For this reason only tensile tests of the auxetic-chiral and hexagonal cellular structures are presented in this article. Specimens with the shape shown in Fig. 1 were cut from 2 mm thick rolled plate of Al7075-T651 alloy. The specimens were cut with a multipurpose CNC abrasive water-jet machine to prevent formation of the heat-affected zone (HAZ) at the cut edges, which is a characteristic of laser-cutting machines. Since the material in the HAZ is very brittle it would influence the fatigue-life significantly. The edges of the specimen in the central reference measurement area were cut with a fine precision to reduce the roughness of the cut surface. No additional surface finish was applied after the water-jet cutting process. All the specimens were oriented in the direction of rolling of the aluminium sheet plate.

As most thin links occur in the central matrix of nine cells it is expected that the static (and fatigue) damage will occur in the central part of the specimens. The smallest total cross-section of the longitudinally oriented links between the structural nodes is $13.3 \mathrm{~mm}^{2}$. At the transition zone the total cross-section of the longitudinal links then rapidly rises. Despite the precise cutting procedure some geometrical inconsistencies emerge at the link edges near the structural nodes. These anomalies are considered later in the finite-element models. To account for their influence the cut specimens were precisely scanned and the scanned edges were modelled with NURBS curves in AutoCAD. In this manner real-shape geometries were obtained for each of the three planar cellular structures.

Static and dynamic experiments were performed on a hydraulic test stand MTS with a $\pm 100 \mathrm{kN}$ loading capacity. The force was measured with a $100 \mathrm{kN}$ MTS load cell and the displacements were measured with an MTS certified videoextensometer module. To apply the video extensometer, black dots were marked at the end of the cellular transition zones at the end of the specimen (Fig. 1). The distance between the two black spots represents a reference length $l_{0}$ that was measured using a calibration template plate. The reference lengths $l_{0}$ for the three types of specimens are presented in Table 1. The static tensile tests were carried out according to the ASTM E8/E8M standard with a loading velocity of 0.5 $\mathrm{mm} / \mathrm{min}$. The tests were performed at an ambient temperature of $23{ }^{0} \mathrm{C}$. Two specimens were tested for each cellular structure.

The ruptures of the specimens from the tensile tests are shown in Fig. 1 and Fig. 7. We can see from these figures that the line connecting the ruptures at the longitudinal links is inclined towards the transverse axis of the specimen for the hexagonal specimens. All the ruptures were at the points where the geometry changes, i.e. in the middle of the longitudinal links or at the structural nodes. From the tensile tests it can be concluded that the auxetic-chiral structure is 
the most flexible structure and that the rupture line is horizontal in a transverse direction with the longitudinal links broken in the middle at the curved spots. The rupture points were the same for both repetitions of the tensile tests on the auxetic-chiral structure.

In Fig. 3 the force-displacement $F$ - $\Delta l$ diagrams of the static tensile tests are presented. The repeatability of the results is good with a low scatter of measured characteristics. Similar trends of the force-displacement $F-\Delta l$ characteristics can be observed for the hexagonal and classic auxetic structures. The classic-auxetic structure is the most rigid with the highest tensile rupture limit. The auxetic-chiral structure is the most flexible, so with its shape the objective of high flexibility and a negative Poisson's ratio was achieved.

Fig. 3. Force-displacement diagrams of the static tensile tests: (A) auxetic-chiral structure, (B) auxetic structure and

\section{(C) hexagonal honeycomb structure}

\subsection{Poisson's ratio}

The Poisson's ratios for the three cellular structures were estimated from measurements of displacements in the central area ( 3 by 3 cells) of the specimen using the video extensometer. From the examples in Fig. 4, the Poisson's ratio for the auxetic-chiral structure is calculated using the following equation:

$v=-\frac{\varepsilon_{y}}{\varepsilon_{x}}=-\frac{0.7 / 44.1}{5.2 / 34.1}=-0.1$

where $\varepsilon_{x}$ is a nominal strain in the longitudinal direction of the specimen and $\varepsilon_{y}$ is a nominal strain in the transverse direction of the specimen. Therefore, the auxetic-chiral structure has a negative Poisson's ratio and the hexagonal structure has a positive Poisson's ratio of 1.0. We can see in Fig. 4 that the positive stretches of the auxetic-chiral structure are significant and approximately equally distributed along the cells in both the longitudinal and lateral directions. The positive stretch for the hexagonal structure is only in the longitudinal direction. The Poisson's ratio of classic auxetic structure is -0.27 [4]. The Al7075-T651 alloy has a Poisson's ratio of 0.33 [14]. The characteristics of the three cellular structures are presented in Table 1 . The cell porosity data in Table 1 were obtained using the following equation:

$p=\frac{A_{\text {pores }}}{A_{\text {total }}}=\frac{A_{\text {pores }}}{A_{\text {pores }}+A_{\text {basic_materal }}}$

Fig. 4. Video-extensometer images for tensile tests of: (A) auxetic-chiral structure and (B) hexagonal structure 
Table 1. Characteristics of the cellular structures

\begin{tabular}{|c|c|c|c|c|}
\hline & Total porosity share $p$ & $\begin{array}{c}\text { Porosity share in the middle } \\
\text { section of the specimen } \\
(3 \times 3 \text { cells })\end{array}$ & $\begin{array}{c}\text { Reference length } \\
l_{0}[\mathrm{~mm}]\end{array}$ & $\begin{array}{c}\text { Poisson's ratio } \\
v[/]\end{array}$ \\
\hline Auxetic-chiral & 0.557 & 0.639 & 100.04 & -0.1 \\
\hline Auxetic & 0.539 & 0.624 & $106.59[4]$ & $-0.27[4]$ \\
\hline Hexagonal & 0.547 & 0.62 & 96.24 & 1 \\
\hline
\end{tabular}

\subsection{Low-cycle fatigue life}

Low-cycle fatigue experiments were carried out on the $100 \mathrm{kN}$ MTS test stand. The specimen geometry was the same as for the static tests. The uniaxial tests were fully reversal and strain controlled $\left(R_{\varepsilon}=-1\right)$ with a Mode I loading condition according to the ASTM E606 standard. The loading frequency was $0.2 \mathrm{~Hz}$ and the ambient temperature was $23{ }^{\circ} \mathrm{C}$. The loading amplitudes were selected according to the force-displacement diagrams from Fig. 3 in Section 2.1. In each diagram in Fig. 3, the loading amplitudes are marked with a circle on the force-displacement characteristic. The displacement amplitudes for the auxetic-chiral structure were $\Delta l= \pm 4, \pm 2, \pm 1.5, \pm 1.3 \mathrm{~mm}$ and $\Delta l= \pm 1.3, \pm 0.65, \pm 0.5$, $\pm 0.45 \mathrm{~mm}$ for the hexagonal structure. Previously measured displacement amplitudes for the classic auxetic structure are $\Delta l= \pm 1, \pm 0.5, \pm 0.4, \pm 0.35 \mathrm{~mm}$ [4]. Since the dynamic loading was fully reversal and the specimens were relatively thin $(t$ $=2 \mathrm{~mm}$ ) a special antibuckling device was used to prevent out-of-plane bending of the specimens (Fig. 5). To reduce the friction, a $0.1 \mathrm{~mm}$ thin PTFE foil was inserted between the specimen and the guiding device, which reduced the friction coefficient to 0.04 . The crack initiation and growth until the final rupture of the cellular specimen was tracked with the camera of the video extensometer. The picture sampling rate was 1 frame/s. The dynamic test was finished after complete separation of the cells in the central part of the specimen. The experimentally determined numbers of loading cycles to failure are presented in Table 2. Despite the low-cycle fatigue cracks of the hexagonal structure being in the central part ( $3 \times 3$ cells) of the specimens, where the material links are the thinnest, the crack positions in the links are rather random. On the other hand, the positions of the low-cycle fatigue cracks in the auxetic-chiral structure are more predictable. In three out of four cases the rupture line is in the transverse direction in the central part ( $3 \times 3$ cells) of the specimen. In only one case the fatigue rupture was combined in two different layers of cells (Fig. 11). The results for the classic auxetic structure have already been presented and discussed by Tomažinčič et al. [4].

Fig 5. Experimental arrangement for low-cycle fatigue experiments of cellular structures 


\section{Numerical simulations}

\subsection{Static rupture of auxetic, auxetic-chiral and hexagonal structures}

Durability prediction is independent of the initial crack in the numerical model when using the CDM method. Furthermore, a total loading spectrum can be applied to track the evolution of the growing crack(s). When predicting the static durability of the cellular structures, the approach of Hooputra et al. [15] was followed. Although it was validated only on standard-shape specimens [16], here it has been extended to complex planar structures, which can have a negative Poisson's ratio. The main advantage of this method is that it enables simulation of the actual separation of critically loaded parts. The applied technique Damage Evolution and Element Removal is based on degradation of the finiteelement rigidity, the elements being eventually removed from the finite element (FE) model if the rigidity degradation reaches a critical value. With no stiffness present at the position of the removed finite element, stress reallocation occurs and the rupture propagates to the next most critical spot. In this manner a more realistic propagation of cracks is possible using finite element models.

Previously, SEM analysis of the ruptured cross-sections of Al7075-T651 specimens [4] showed that the damage mechanism consisted of void nucleation, growth and coalescence [17,18]. This damage mechanism is known as Ductile Damage and is implemented into the FE software Abaqus [19]. When simulating the elastic-plastic damage of materials the damage evolution is linked by two criteria: i) the damage initiation criterion and ii) the damage evolution criterion, which are followed separately. According to current research [20,21] three parameters have the most influence on damage initiation: fracture strain $\bar{\varepsilon}_{f}^{p l}$ (as determined from Fig. 6-A); stress triaxiality $\eta$; and strain rate $\dot{\varepsilon}$ (which follows from the loading rate). The stress triaxiality $\eta$ is a ratio of the hydrostatic stress $-p$ and an effective Von-Mises stress $q$ :

$\eta=\frac{-p}{q}=\frac{\frac{1}{3}\left(\sigma_{1}+\sigma_{2}+\sigma_{3}\right)}{\sqrt{\frac{1}{2}\left[\left(\sigma_{1}-\sigma_{2}\right)^{2}+\left(\sigma_{2}-\sigma_{3}\right)^{2}+\left(\sigma_{3}-\sigma_{1}\right)^{2}\right]}}$

where $\sigma_{1}, \sigma_{2}$ and $\sigma_{3}$ are the three principal stresses. The stress triaxiality factor $\eta$ was determined with separate FE simulations using the output variable TRIAX in Abaqus. In all the FE simulations, stress triaxiality factors $\eta$ were applied that were determined from the most critical spots of these analyses (Fig. 7). A yield strength $\sigma_{y}$ of $530 \mathrm{MPa}$ and an ultimate tensile strength $\sigma_{u}$ of $596 \mathrm{MPa}$ for the Al7075-T651 alloy were measured previously with standard tensile tests [4].

The point of damage initiation is linked to the maximum stress $\sigma=F / A_{0}$ in the measured engineering stress/strain diagram. After damage initiation, the damage in the material has evolved and can be assessed in the form of a damage 
parameter $D=A_{D} / A_{0}$, where $A_{0}$ is the original cross-section and $A_{D}$ is a damaged cross-section. The damage parameter $D$ ranges from 0 (no damage) to 1 (full damage). The maximum damage permitted is set-up under the option of Max Degradation in the Abaqus software.

From the damage initiation two material characteristics can be determined: i) the softening of the material (and therefore the real stress $\sigma$ ) as represented by the damage response curve and ii) the hypothetical stress $\bar{\sigma}$ in the material without micro cracks as represented by the undamaged response. The latter stress can be estimated as $\bar{\sigma}=F /\left(A_{0}-A_{D}\right)$ from Fig. 6-A through a separate FE analysis. With the help of a reduction factor (1-D) the real (softened) stress can be calculated from Fig. 6-A as $\sigma=(1-D) \bar{\sigma}$.

\section{Fig. 6. Elastic-plastic response of the base material Al7075-T651 with an analysis of the progressive damage}

When using the CDM method, stress analysis has an important role and depends on the mesh density. To reduce this dependence, the finite-element size is linked to the elongation at failure. The equivalent displacement at failure, which defines the damage evolution via the evolution law, is calculated as $\bar{u}_{f}^{p l}=L_{c h} \cdot \bar{\varepsilon}_{f}^{p l}$. The equivalent plastic strain at failure $\bar{\varepsilon}_{f}^{p l}$ is estimated using the static tensile curves of the base material shown in Fig. 6-A. $L_{c h}$ is a characteristic finite-element length calculated as the ratio between the volume of the finite element and its largest face area. Hence the quality of the finite elements is more important than the mesh density.

For this reason a structured mesh of C3D8R finite elements was applied wherever possible, i.e. for the auxetic-chiral and hexagonal structures. The average size of the finite-element edges was $0.4 \mathrm{~mm}$ for all three cellular structures. The mesh was extruded from the meshed top faces of the specimens that were obtained as described in Section 2.1.

The criterion of initial damage is fulfilled if [19]:

$\Delta \omega_{D}=\frac{\Delta \bar{\varepsilon}^{p l}}{\bar{\varepsilon}_{D}^{p l}} \geq 0$

where $\bar{\varepsilon}_{D}^{p l}$ is the equivalent plastic strain at damage initiation and $\Delta \bar{\varepsilon}^{p l}$ is the strain increment during the test. After the initial damage is triggered, damage evolution occurs, which is represented by a scalar parameter [19]:

$d=\frac{1-e^{-\alpha\left(\bar{u}^{p l} / \bar{u}_{f}^{p l}\right)}}{1-e^{-\alpha}}$

Damage evolution can be modelled using two different approaches: i) the criterion of the maximum effective plastic displacement at failure $\bar{u}^{p l}$ or ii) the criterion of maximum dissipated fracture energy per unit area at failure $G_{f}$, which is defined as follows: 
$G_{f}=\int_{0}^{\bar{u}_{f}^{p l}} \sigma_{y} d \bar{u}^{p l}$

The damage occurs when the value $d$ from Equation 5 is equal to 1 at all the FE integration points. The damage evolution path can be linear $(\alpha=0)$ or exponential $(\alpha>0)$, where $\alpha$ is the damage evolution parameter in the Abaqus software. We have adopted both approaches when simulating the static tensile test. The value of $G_{f}$ in the simulations that follow from Fig. 6 was equal to $20.1 \mathrm{~N} / \mathrm{mm}$.

The reference method for simulating the damage and crack evolution was an element removal technique in combination with either the implicit or explicit Abaqus solver. After the numerical results were obtained using the reference FE methods they were checked with an alternative approach, i.e. XFEM [22] using the implicit Abaqus solver. The XFEM approach used an automatic initial crack forming on the critical specimen cross-sections. Within the material model, the Damage for Traction Separation Laws option was applied. The maximum principal stresses for this option were calculated via additional FE simulation. The displacement at failure $\bar{u}_{f}^{p l}$ was defined in the same manner as explained previously. Complete consistency of the initial cracks predicted by the reference (Explicit/Element Removal) and the alternative (Implicit/XFEM) FE approaches is observed (Fig. 7). To avoid convergence problems related to the implicit XFEM method, the reference method was applied in the continuation of the numerical simulations, i.e. the damage evolution and element removal in combination with the Abaqus explicit solver.

Fig. 7. A comparison of experimental (left) and numerical (right) results of tensile tests; initial cracks obtained with different FE methods are presented above; (a-test 1, b-test 2)

\subsection{Prediction of fatigue life for ultra-low cycle fatigue experiments}

The application of the element removal method from Hooputra et al. [15] in Section 3.1 represents a step forward in understanding the damage evolution, because it is possible to identify critical spots in complex structures on the basis of the separation of structural parts. For this reason this technique has also been applied to simulating the resilience of cellular structures to dynamic loading in the elastic-plastic regime where a significant portion of the strain amplitude comes from the plastic strain domain. Such a loading condition is known in the literature as ultra-low cycle fatigue loading [23-25]. Its main feature is that the number of load cycles to failure is very low, generally less than ten cycles. Contrary to the research of Nečemer et al. [26], it was decided that damage evolution in the ultra-low cycle regime would be modelled solely on the basis of the dissipated strain energy during the cyclic loading. To predict the fatigue life, the same FE and ductile damage material models were applied as in Section 3.1. The criterion for damage initiation was the same as for the simulations of the tensile test, however modelling of the damage evolution stage was different. The basic 
presumption was that the maximum dissipated fracture energy per unit area at failure $G_{f}$ is equal, as was the case for the tensile test, i.e. $20.1 \mathrm{~N} / \mathrm{mm}$ (see Section 3.1 and Fig. 6-A). The key modification of the material model for the ultra-low cycle fatigue experiments is based on the presumption that the fatigue crack propagates only during the tensile loading phase [19]. For this reason the initial fracture strain in a compressive regime was defined as twice the corresponding value in the tensile regime. By defining the material parameters in this way, crack propagation during the compressive loading phase was prevented. To study the damage evolution and crack propagation, the FE model was loaded with repetitive fully reversal loading cycles until the complete separation of the specimen into two parts. The ultra-low cycle fatigue simulations were carried out only for the highest loading level for each of the three cellular structures.

\subsection{Prediction of fatigue life on the basis of a linear damage-accumulation rule}

To predict the fatigue life for more than only a few loading cycles the processing time for damage evolution methods, as described in Section 3.2, would be prohibitive. For this reason a linear damage-accumulation rule was implemented, based on low-cycle fatigue theory $[27,28]$. When following this approach, the reversal points of the dynamic loading are modelled first using a stabilised cyclic curve to obtain the stress-strain state in the structure. Then the fatigue damage is predicted using the linear damage-accumulation rule according to a defined elastic-plastic fatigue durability curve $[29,30]$. Since the implicit FE code was used to obtain the stress-strain distribution in the specimens, the FE mesh of the three cellular structures was different to those used in Sections 3.1 and 3.2. In this case the full 3D models of the specimens were built by extrusion of the top surface in Catia V5 3D modeller. These 3D models were then imported into Abaqus where they were meshed by C3D8R finite elements. To avoid poor finite elements at geometric hot spots and consequently unrealistic stress/strain peaks, a Saint-Venant principle of mesh densification was used. The number of finite elements and nodes for the three cellular structures were as follows: 141174 finite elements and 182236 nodes for the auxetic-chiral structure and 111468 finite elements and 143038 nodes for the hexagonal structure. Details of the FE mesh for the classic auxetic structure can be found in Tomažinčič et al. [4]. The applied material model was a multi-linear plasticity model with kinematic hardening. The elastic modulus was $E=71500 \mathrm{MPa}$, a Poisson's ratio of 0.33 and a material density of $2.7 \mathrm{~g} / \mathrm{cm}^{3}$ [4]. The points for the multi-linear plasticity model were defined on the basis of the Ramberg-Osgood cyclic curve:

$$
\varepsilon=\frac{\sigma}{E}+\left(\frac{\sigma}{K^{\prime}}\right)^{\frac{1}{n^{\prime}}}
$$

Its parameters $n^{\prime}$ and $K^{\prime}$ were estimated on the basis of the engineering stress-strain cyclic curve in Fig. 6-A. Before estimating these two parameters, the $\sigma-\varepsilon$ cyclic curve in Fig. 6-A was transformed into the true stress-strain form [14]. In this manner the following parameters for the Ramberg-Osgood curve were estimated: $K^{\prime}=816 \mathrm{MPa}, n^{\prime}=0.0657$ [4]. The 
boundary conditions were as follows: the FE model was fixed at one side and loaded with a pre-specified displacement function at the other side. Two consecutive loading cycles were simulated using the implicit Abaqus solver. The reversal points from the second loading cycle were considered as a reference for calculating the low-cycle fatigue damage.

The fatigue lives of the specimens were predicted using the SIMULIA fe-safe software. The input to the SIMULIA fesafe software is the simulated stress-strain distribution for the two relevant reversal points. A criterion for estimating the fatigue lives was the Coffin-Manson durability curve [31,32] for 50\% probability of rupture, which was obtained from a series of fully reversal strain- and stress- controlled fatigue experiments on standard specimens carried out on the Al7075T651 alloy. The parameters of the Coffin-Manson curve were as follows: $b=-0.0048, c=-0.3605, \varepsilon_{f}^{\prime}=0.0686$ and $\sigma_{f}{ }^{\prime}=$ 114.5 MPa [4] and the influence of micro geometrical irregularities were considered by applying a surface roughness parameter $\kappa_{t}=1.05$ [33]. The strain amplitudes used for fatigue-life predictions were determined by a critical plane approach for each finite element. As was already discovered by Tomažinčič et al. [4] the best fatigue-life predictions for the classic auxetic structure were obtained using either the Brown-Miller criterion with a Morrow correction for the mean stress [33,34]:

$$
\frac{\Delta \gamma}{2}+\frac{\Delta \varepsilon_{n}}{2}=1.65 \frac{\left(\sigma_{f}^{\prime}-\sigma_{m}\right)}{E}\left(2 N_{f}\right)^{b}+1.75 \varepsilon_{f}^{\prime}\left(2 N_{f}\right)^{c}
$$

or the original Coffin-Manson criterion with the Morrow correction for the mean stress [19,35]:

$$
\frac{\Delta \varepsilon}{2}=\frac{\left(\sigma_{f}^{\prime}-\sigma_{m}\right)}{E}\left(2 N_{f}\right)^{b}+\varepsilon_{f}^{\prime}\left(2 N_{f}\right)^{c}
$$

where $\Delta \gamma$ is the shear strain range and $\Delta \varepsilon$ is the normal strain range. Both approaches were also applied to the auxeticchiral and hexagonal structures. Using the Palmgren-Miner rule the fatigue damage per loading cycle and the number of loading cycles to failure $N$ are linked by the following equation [29]:

$$
N=\frac{1}{\text { Damage }}
$$

\section{Results and discussion}

\subsection{Static tests}

In Fig. 7 a comparison between the simulation and experimental results is shown for the tensile tests of the three cellular structures. The fracture spots predicted by simulations agree well with the actual fracture spots from the tensile tests. The agreement of the simulated and real fracture spots is almost perfect for the auxetic-chiral structure (Fig. 7-A) and the hexagonal structure (Fig. 7-C). A diagonal rupture line for the hexagonal structure was confirmed by the simulations. A significant plastic deformation of the links can be observed near the fracture spots in the middle of the specimen. The 
highest measured elasticity of the auxetic-chiral structure as well as its transverse rupture line were confirmed by the simulations. The simulated displacements of this cellular structure also confirm its negative Poisson's ratio. For the classic auxetic structure three out of four fracture spots were correctly predicted by the simulations, and in addition, the simulation results have confirmed the central diagonal line of rupture obtained by the static tensile experiments (Fig. 7B).

\subsection{Ultra-low cycle fatigue simulations and experiments}

Here, only the low-cycle fatigue experiments at the highest loading levels are considered as an ultra-low cycle fatigue phenomenon: $\Delta l= \pm 4 \mathrm{~mm}$ for the auxetic-chiral structure, $\Delta l= \pm 1 \mathrm{~mm}$ for the classic auxetic structure and $\Delta l= \pm 1.3 \mathrm{~mm}$ for the hexagonal structure. The fatigue lives at the fully reversal displacement controlled loads were two to three loading cycles (Fig. 8).

Fig. 8. Results of low-cycle fatigue experiments at the highest loading levels

In each of the three cases the final rupture was in the tensile part of the loading cycle. Sudden rupture of all the connecting links occurred in both the auxetic-chiral and hexagonal structures, whereas fracture of the classic auxetic structure is gradual. In the latter, three out of four longitudinal links ruptured initially, but the remaining link was gradually broken during the next two loading cycles. From Fig. 8 it can be observed that the mean stress was shifted to a positive value despite fully reversal displacement loading. The nominal maximum stresses at the smallest cross-sections of the three structures were $120 \mathrm{MPa}$ for the auxetic-chiral structure, $290 \mathrm{MPa}$ for the classic auxetic structure and 220 MPa for the hexagonal structure. However, the notched stresses around the structural hot spots are much higher (more than $600 \mathrm{MPa}$ ), which can be seen from the results of the FE simulations in Fig. 10 and Table 2.

The results of simulations for the three ultra-low cycle fatigue cases are presented in Fig. 9. When following the pictures from the left to the right a gradual rupture of the material indicated by the removed finite elements can be observed. The final separation of the specimen into two parts is achieved after three loading cycles for the auxetic-chiral and classic auxetic structures, whereas it took only two loading cycles for complete separation of the hexagonal structure. The predicted loading cycles are very close to the experimental results.

Fig. 9. Results of ultra-low cycle fatigue simulations using the damage evolution method combined with element removal

The suitability of the energy approach for predicting ultra-low cycle fatigue life can be validated using the dissipatedenergy curves (Fig. 6-B and Fig. 6-C). The dissipated energy (ALLPD output from Abaqus) constantly rises until the 
final rupture of the specimen in Fig. 6-B. On the basis of the ALLPD output from the simulations we can confirm the ultra-low cycle fatigue rupture happened at the same maximum dissipated fracture energy per unit area at failure $G_{f}$ as for the tensile-test simulations. The simulated dissipated energy per loading cycle in Fig. 6 -B $\left(G_{f, c y c l e}=6.87 \mathrm{~N} / \mathrm{mm}\right.$ for the auxetic-chiral structure, $G_{f, c y c l e}=7.62 \mathrm{~N} / \mathrm{mm}$ for the classic auxetic structure and $G_{f, c y c l e}=9,84 \mathrm{~N} / \mathrm{mm}$ for the hexagonal structure) has the same order of magnitude as the dissipated energy per loading cycle calculated from the experiments.

In Fig. 6-C an envelope of the expected simulated fatigue life is shown for the ultra-low cycle domain. The upper boundary of the envelope was determined by a regression line in $\log \varepsilon-\log N$ space through all the fatigue-life experiments for the base material [4], for which the plastic strain-energy density range was larger than the positive elastic strainenergy range: $\Delta W_{p}>\Delta W_{e+}$. The lower boundary of the envelope was determined by another regression line through all the fatigue-life experiments for the base material, for which the plastic strain-energy density range was four times bigger than the positive elastic strain-energy range: $\Delta W_{p}>4 \cdot \Delta W_{e+}$. From the simulated dissipated energies per loading cycle together with the number of corresponding load cycles to failure shown in Fig 6-C, it can be seen that all the results fall in the vicinity of the lower boundary of the envelope $\left(\Delta W_{p}>4 \cdot \Delta W_{e+}\right)$, which confirms the suitability of the energy-based approach for predicting ultra-low cycle fatigue life.

\subsection{Low-cycle fatigue simulations and experiments}

Stress distributions in the auxetic-chiral structure for different points in the loading time series (Fig. 10) show that significant plastification occurs during dynamic loading since the residual stresses after two loading cycles reach a value of $603 \mathrm{MPa}$.

Fig. 10. Stress distribution in auxetic-chiral structure at maximum loading level $\Delta l= \pm 4$ mm: (A) unloaded state after the $1^{\text {st }}$ loading cycle; (B) the next reversal point in compression; $(C)$ the next reversal point in tension

In Figs. 11 and 12 the predicted logarithmic fatigue lives for the auxetic-chiral and the hexagonal structures are shown for the four loading levels. The logarithmic fatigue lives below a value of 2 (the critical spots) are shown in white colour. We can see in these two figures that the higher loading levels result in larger areas of critical spots - loading case (A). Lower fatigue lives correspond to the areas of damage initiation. From these areas the predicted numbers of loading cycles to failure were determined (Table 2).

Fig. 11. Predicted logarithmic fatigue-life with the Brown-Miller (Morrow) model for the auxetic-chiral structure for the four loading levels: (A) $\Delta l= \pm 4 \mathrm{~mm}$; (B) $\Delta l= \pm 2 \mathrm{~mm}$; (C) $\Delta l= \pm 1.5 \mathrm{~mm}$; (D) $\Delta l= \pm 1.3 \mathrm{~mm}$

Fig. 12. Predicted logarithmic fatigue-life with the Brown-Miller (Morrow) model for the hexagonal structure for the four loading levels: (A) $\Delta l= \pm 1.3 \mathrm{~mm}$; (B) $\Delta l= \pm 0.65 \mathrm{~mm}$; (C) $\Delta l= \pm 0.5 \mathrm{~mm}$; (D) $\Delta l= \pm 0.45 \mathrm{~mm}$ 
Table 2: Comparison of fatigue lives for the auxetic-chiral and hexagonal structures

\begin{tabular}{|c|c|c|c|c|c|c|}
\hline Structure & $\begin{array}{c}\text { Loading } \\
\text { level }\end{array}$ & $\begin{array}{l}\text { Displacement } \\
\text { range } \\
\Delta l[\mathrm{~mm}]\end{array}$ & $\begin{array}{c}\text { Max. Von- } \\
\text { Mises stress } \\
{[\mathrm{MPa}]}\end{array}$ & $\begin{array}{c}\mathrm{N}-\text { Brown-Miller } \\
\text { (Morrow) } \\
\text { prediction }\end{array}$ & $\begin{array}{c}\mathrm{N}-\text { Coffin- } \\
\text { Manson (Morrow) } \\
\text { prediction }\end{array}$ & $\begin{array}{c}\mathrm{N}- \\
\text { Experimental } \\
\text { determined } \\
\text { fatigue life }\end{array}$ \\
\hline \multirow{4}{*}{$\begin{array}{c}\text { Auxetic- } \\
\text { chiral }\end{array}$} & A & \pm 4 & 603 & $\begin{array}{c}1 \\
(-4.978 *)\end{array}$ & $\begin{array}{c}1 \\
(-4.982 *)\end{array}$ & 3 \\
\hline & B & \pm 2 & 601 & $\begin{array}{c}74 \\
(1.872 *)\end{array}$ & $\begin{array}{c}88 \\
(1.943 *)\end{array}$ & $40(54)^{* *}$ \\
\hline & $\mathrm{C}$ & \pm 1.5 & 576 & $\begin{array}{c}156 \\
\left(2.193^{*}\right)\end{array}$ & $\begin{array}{c}179 \\
\left(2.254^{*}\right)\end{array}$ & 149 \\
\hline & $\mathrm{D}$ & \pm 1.3 & 559 & $\begin{array}{c}185 \\
(2.268 *)\end{array}$ & $\begin{array}{c}214 \\
\left(2.330^{*}\right)\end{array}$ & $255(362) * * *$ \\
\hline \multirow{4}{*}{ Hexagonal } & A & \pm 1.3 & 612 & $\begin{array}{c}1 \\
(-4.894 *)\end{array}$ & $\begin{array}{c}1 \\
(-4.963 *)\end{array}$ & 2 \\
\hline & B & \pm 0.65 & 609 & $\begin{array}{c}59 \\
(1.769 *)\end{array}$ & $\begin{array}{c}68 \\
(1.832 *)\end{array}$ & 31 \\
\hline & $\mathrm{C}$ & \pm 0.5 & 602 & $\begin{array}{c}98 \\
\left(1.993^{*}\right)\end{array}$ & $\begin{array}{c}113 \\
(2.052 *)\end{array}$ & $130 * * * *$ \\
\hline & D & \pm 0.45 & 599 & $\begin{array}{c}103 \\
(2.011 *)\end{array}$ & $\begin{array}{c}116 \\
\left(2.065^{*}\right)\end{array}$ & 462 \\
\hline
\end{tabular}

* Numerically predicted logarithmic fatigue life [/]

** Number of cycles at full separation of the specimen

*** Until loading cycle 333 the force amplitude was constant then gradually reduced until loading cycle 362, when the force amplitude reached half of its initial value

**** The force reduction was constant (up to $20 \%$ ) at 130 cycles, where a sudden rupture occurred

The distribution of critical spots is well dispersed for the auxetic-chiral structure, which means that the material use is efficient. The transverse links of the hexagonal structure are less loaded than its longitudinal links. This leads to multiple failures in the longitudinal links with the transverse links being almost untouched (Fig. 12-C).

A unified comparison of the predicted and measured low-cycle fatigue lives is presented in Fig. 13. It can be concluded from this figure that generally better fatigue-life predictions are obtained at lower loading levels, which result in less plastic-energy dissipation.

Fig. 13. Comparison of experimentally determined and numerically predicted fatigue lives of the cellular structures

\section{Conclusions}

On the basis of experiments and numerical predictions of cellular-structure durability the following can be concluded:

- The auxetic-chiral structure, which was derived from the classic auxetic structure, has a predictable rupture of the intercellular links. The tensile and fatigue fractures occur at inter-cellular links and not at nodal notched geometries. This means the structure is relatively insensitive to local notch effects due to its global geometry. Larger notch effects at certain nodes were more a consequence of the abrasive water-jet cutting process than the basic geometry. 
- If the force-displacement characteristics of the studied cellular structures are compared, it can be concluded that the most similar structures are the classic auxetic structure and the hexagonal structure. Despite the similarity of their shape and porosity level their mechanical behaviour differs with respect to their Poisson's ratios. Namely, the classic auxetic structure has a negative Poisson's ratio, but the hexagonal structure has a positive Poisson's ratio.

- The application of the damage evolution and element removal technique helped us to understand damage and rupture evolution in cellular structures. A consequence of structural ruptures was well modelled using stiffness degradation and the removal of finite elements. This approach is especially advantageous when simulating the structure's response at high loading levels, resulting in significant plastification of the base material, e.g. during tensile and ultra-low cycle fatigue tests. In addition, it is highly convenient that no special custom-made software is needed because the methodology is already built into the FEA software Abaqus.

- When applying the damage evolution and element removal technique the bulk geometry of the structural elements have more influence on the numerical results than the mesh density. For this reason NURBS curves were used to model the real specimen shapes. This approach was successfully validated on the three planar cellular structures.

- We have shown that reasonable low-cycle fatigue-life predictions were obtained for complicated cellular structures if the critical-plane approach was combined with a linear damage accumulation rule and variations of the CoffinManson durability curves. This approach yields better fatigue-life predictions at lower loading levels, which result in smaller shares of the plastic strain amplitudes within the loading cycles. The predictions from the Coffin-Manson and Brown-Miller models are comparable with the latter model being more conservative. The main advantage of this approach is its superiority regarding the processing time at higher numbers of loading cycles when compared to the damage evolution and element removal technique. However, an additional add-on software, e.g. SIMULIA fe-safe, is required for this type of analysis.

\section{Acknowledgements}

The research was performed within the framework of the basic research project J2-8186 entitled "Development of multifunctional auxetic cellular structures”, which is financed by the Slovenian Research Agency “ARRS”. Furthermore, the authors acknowledge the financial support from the Slovenian Research Agency (Research Core Funding No. P20063). 


\section{References}

[1] N. Gaspar, X.J. Ren, C.W. Smith, J.N. Grima, K.E. Evans, Novel honeycombs with auxetic behaviour, Acta Mater. 53 (2005) 2439-2445.

[2] Z. Yuan, F. Li, R. Wang, C. Wang, J. Li, F. Xue, Influence of Poisson's ratio and stress triaxiality on fracture behavior based on elastic strain energy density, Theor Appl Fract Mec. 74 (2014) 96-108

[3] N. Novak, M. Vesenjak, L. Krstulović-Opara, Z. Ren, Mechanical characterisation of auxetic cellular structures built from inverted tetrapods, Compos Struct. 196 (2018) 96-107.

[4] D. Tomažinčič, B. Nečemer, M. Vesenjak, J. Klemenc, Low-cycle fatigue life of thin-plate auxetic cellular structures made from aluminium alloy 7075-T651, Fatigue Fract Eng Mater Struct. 42 (2019) 1022-1036.

[5] A. Alderson, K.L. Alderson, Auxetic materials, Proc Inst Mech Eng G J Aerosp Eng. 221 (2007) 565-575.

[6] F. Scarpa, L.G. Ciffo, J.R. Yates, Dynamic properties of high structural integrity auxetic open cell foam, Smart Mater Struct. 13 (2003) 1.

[7] W.-H. Choi, C.-G. Kim, Broadband microwave-absorbing honeycomb structure with novel design concept, Composites Part B. 83( 2015) 14-20.

[8] X. Hou, V.V. Silberschmidt, Metamaterials with Negative Poisson's Ratio: A Review of Mechanical Properties and Deformation Mechanisms, Springer International Publishing, 2015.

[9] G. Bianchi, S.G. Aglietti, G. Richardson, Static and Fatigue Behaviour of Hexagonal Honeycomb Cores under Inplane Shear Loads, Appl Compos Mater. 19 (2012) 97-115.

[10] S. Belouettar, A. Abbadi, Z. Azari, R. Belouettar, P. Freres, Experimental investigation of static and fatigue behaviour of composites honeycomb materials using four point bending tests, Compos Struct. 87 (2009) $265-273$.

[11] A. J. Österreicher, G. Kirov, S.A.S. Gerstl, E. Mukeli, F. Grabner, M. Kumar, Stabilization of 7xxx aluminium alloys, J Alloy Compd. 740 (2018) 167-173.

[12] M. da Fonte, L. Reis, M. de Freitas, Fatigue crack growth under rotating bending loading on aluminium alloy 7075 T6 and the effect of a steady torsion, Theor Appl Fract Mec. 80 (2015) 57-64.

[13] J.M. Meininger, S.L. Dickerson, J.C. Gibeling, Observation of tension/compression asymmetry in the cyclic deformation of aluminum alloy 7075, Fatigue Fract Eng Mater Struct. 19 (1996) 85-97. 
[14] N.E. Dowling, Mechanical Behaviour of Materials, 4th ed., Pearson, USA, 2013.

[15] H. Hooputra, H. Gese, H. Dell, H. Werner, A Comprehensive Failure Model for Crashworthiness Simulation of Aluminium Extrusions, Int J Crashworthines. 9 (2004) 449-464.

[16] F. Zárate, E. Oñate, A simple FEM-DEM technique for fracture prediction in materials and structures, Comput Part Mech. 2 (2015) 301-314.

[17] A. Weck, D.S. Wilkinson, E. Maire, Observation of void nucleation, growth and coalescence in a model metal matrix composite using X-ray tomography, Mat Sci Eng A-struct. 488 (2008) 435-445.

[18] V.M.T. Navas, M. Bernacki, P.O. Bouchard, Void growth and coalescence in a three-dimensional non-periodic void cluster, Int J Solids Struct. 139-140 (2018) 65-78.

[19] ABAQUS, Abaqus Theory Manual v.6.11, Hibbitt, Karlsson and Sorensen Inc., USA, 2011

[20] M. Kõrgesaar, J. Romanoff, Influence of softening on fracture propagation in large-scale shell structures, Int J Solids Struct. 50 (2013) 3911-3921.

[21] A. AbuBakar, R.S. Dow, Simulation of ship grounding damage using the finite element method, Int J Solids Struct. 50 (2013) 623-636.

[22] L. Zhao, Y. Wang, J. Zhang, Y. Gong, N. Hu, N. Li, XFEM-based model for simulating zigzag delamination growth in laminated composites under mode I loading, Compos Struct. 160 (2017) 1155-1162.

[23] P. Xiang, L.-J. Jia, M. Shi, M. Wu, Ultra-low cycle fatigue life of aluminum alloy and its prediction using monotonic tension test results, Eng Fract Mech. 186 (2017) 449-465.

[24] R. Kiran, K. Khandelwal, A micromechanical cyclic void growth model for ultra-low cycle fatigue, Int J Fatigue 70 (2015) 24-37.

[25] S. Nagel, P. Knödel, T. Ummenhofer, Testing of Ultra-Low Cycle Fatigue at Complex Loading Scenarios, Procedia Structural Integrity. 5 (2017) 1377-1384.

[26] B. Nečemer, J. Kramberger, T. Vuherer, S. Glodež, Fatigue crack initiation and propagation in re-entrant auxetic cellular structures, Int J Fatigue. 126 (2019) 241-247. doi: 10.1016/j.ijfatigue.2019.05.010.

[27] F.Ellyin, Stochastic modelling of crack growth based on damage accumulation, Theor Appl Fract Mec. 6 (1986) 95101. 
[28] S.S. Manson, G.R. Halford, Fatigue and Durability of Structural Materials, ASM International, Materials Park Ohio, USA, 2006.

[29] M.A. Miner, Cumulative damage in fatigue, Int J Appl Mech. 12 (1945) A159-A164.

[30] E. Haibach. Betriebsfestigkeit: Verfahren und Daten zur Bauteilberechnung (VDI-Buch) 3, korrigierte und ergänzte Auflage, Springer, Germany, 2006.

[31] L.F. Coffin, A study of the effects of cyclic thermal stresses on a ductile material, Trans ASME. 76 (1954)931-950.

[32] S.S. Manson, Fatigue: a complex subject - some simple approximations, Exp Mech. 5 (1965) 193-226.

[33] Dassault Systemes. SIMULIA fe-safe, User Guide, 2017.

[34] M.W. Brown, K.J. Miller, A theory for fatigue failure under multiaxial stress-strain conditions, Proc Inst Mech Eng. 187 (1973) 745-755.

[35] S.S. Manson, G.R. Halford, Fatigue and Durability of Structural Materials, ASM International, Materials Park, Ohio, USA, 2006. 

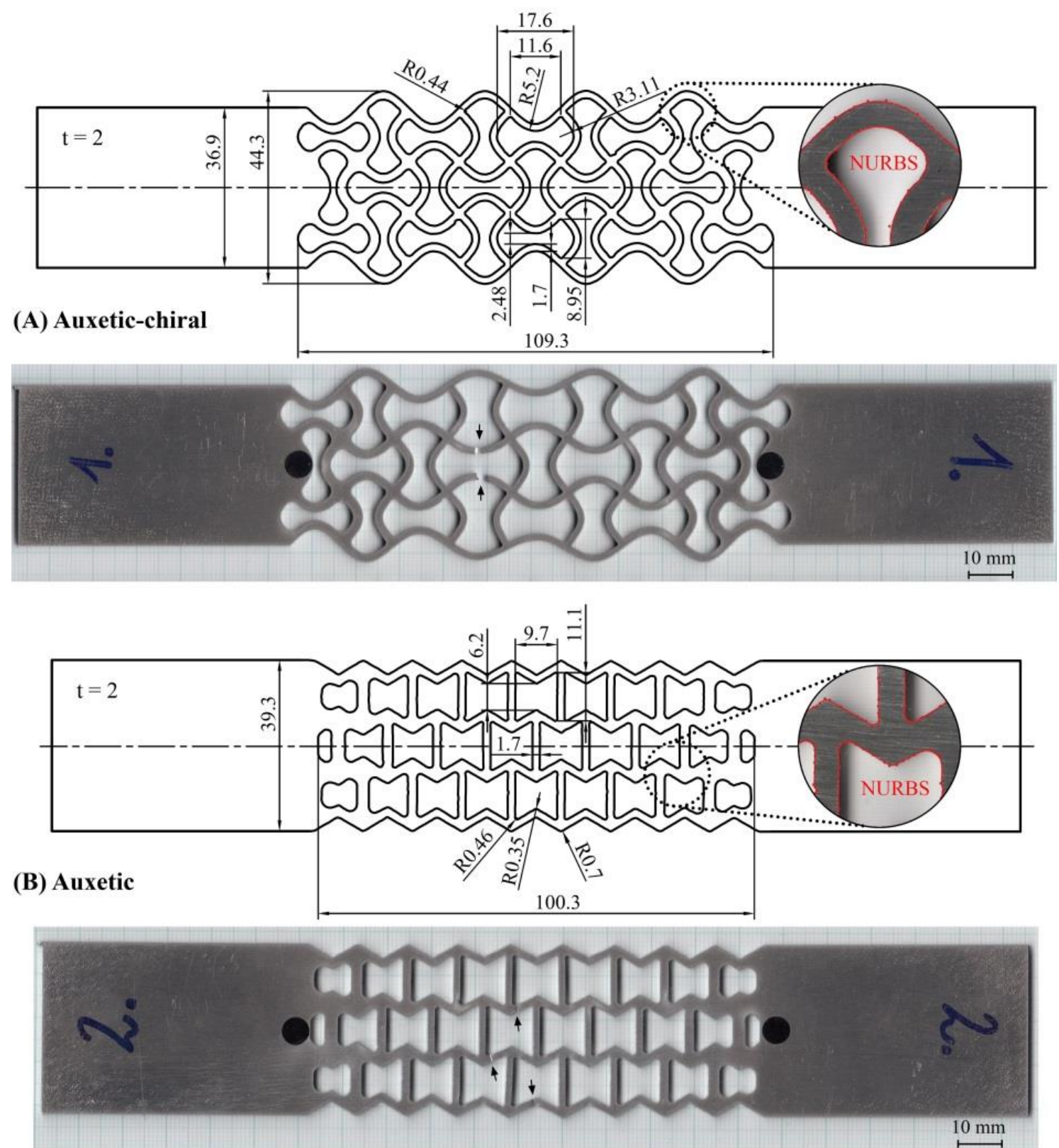

(C) Hexagonal
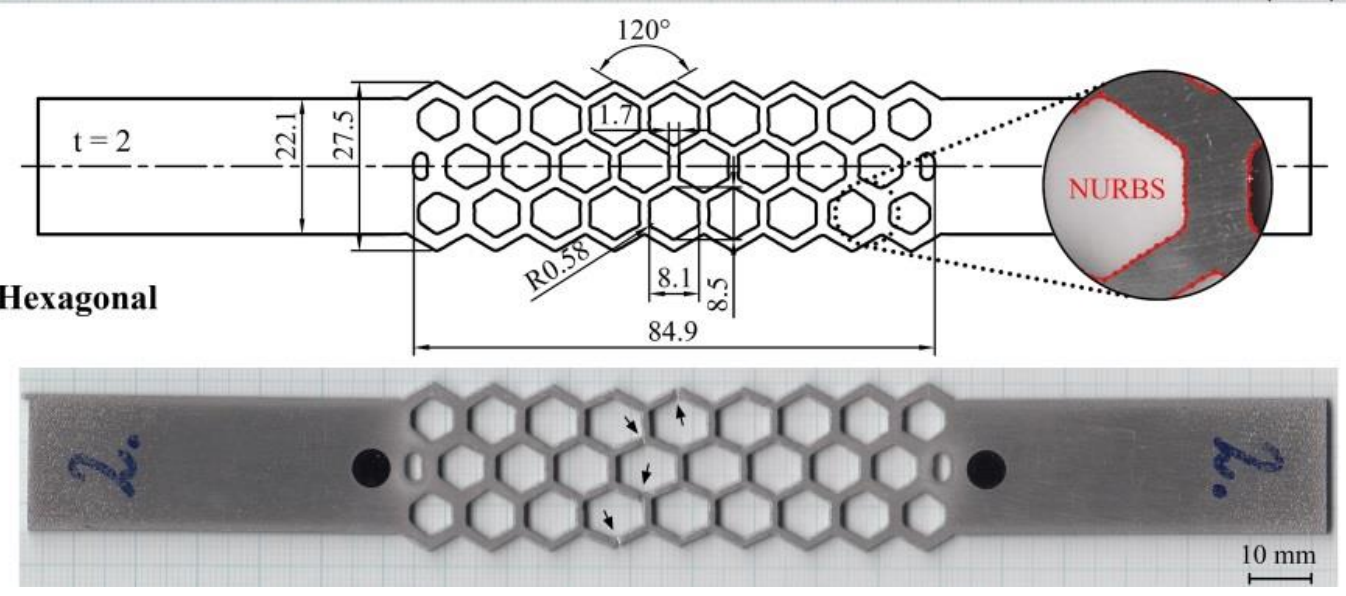

Fig. 1. Geometries and static failures of the planar cellular structures studied in this paper: (A) auxetic-chiral structure, (B) classic auxetic structure, (C) hexagonal honeycomb structure 


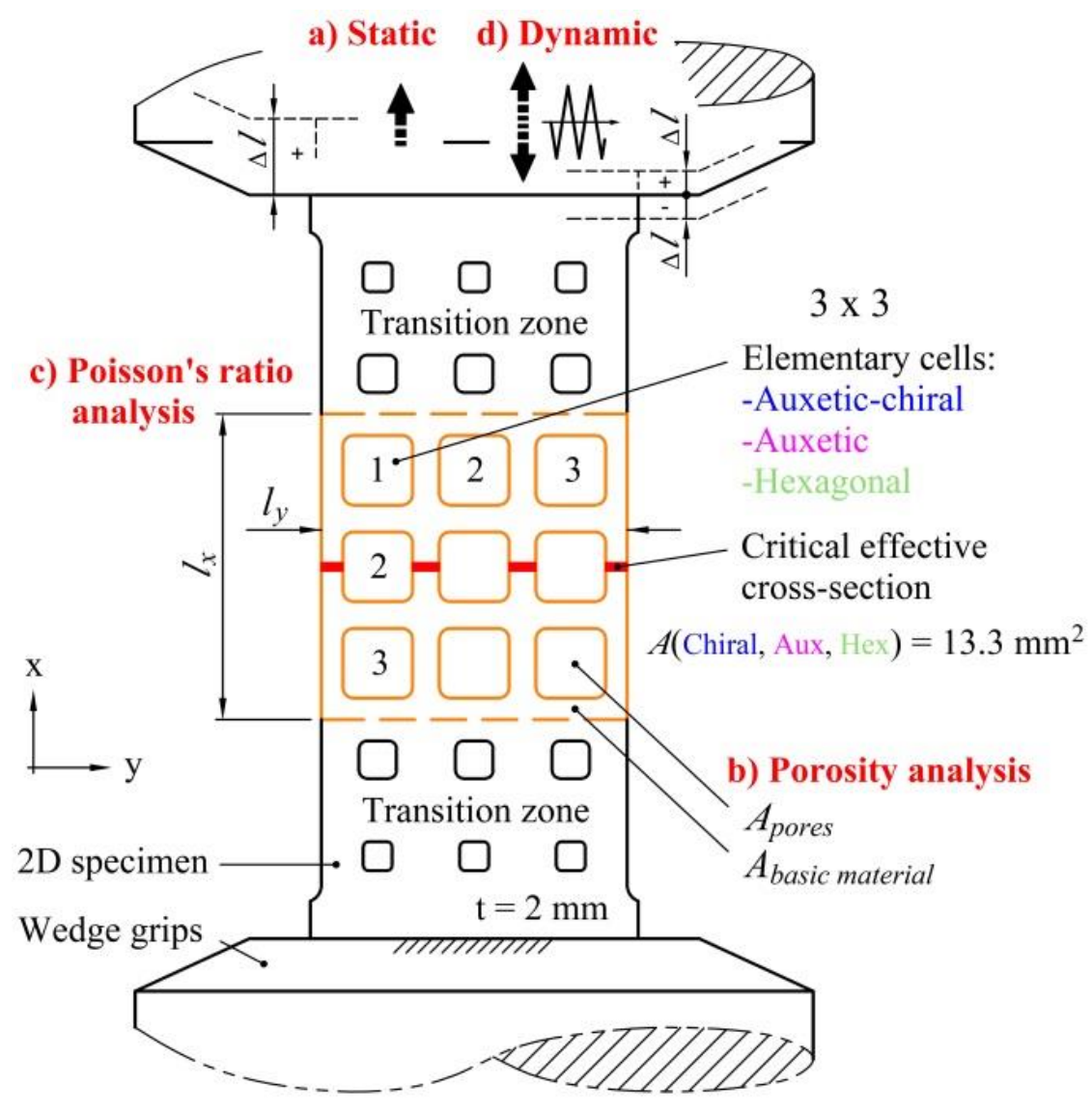

Fig. 2. Experimental arrangement for static and dynamic testing of the planar cellular structures 


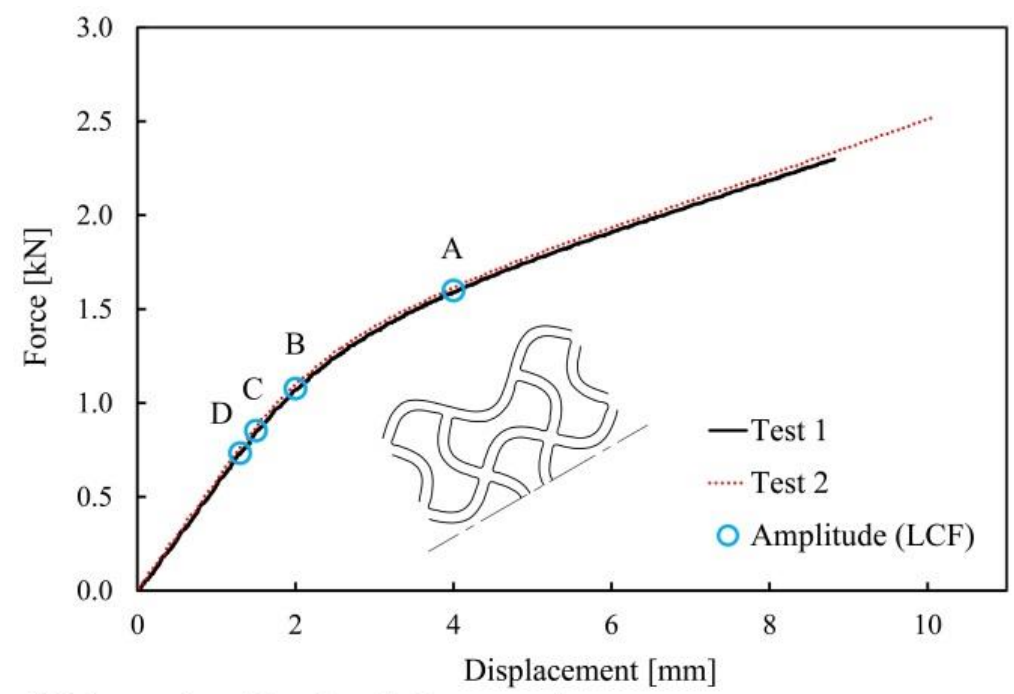

(A) Auxetic-chiral cellular specimen

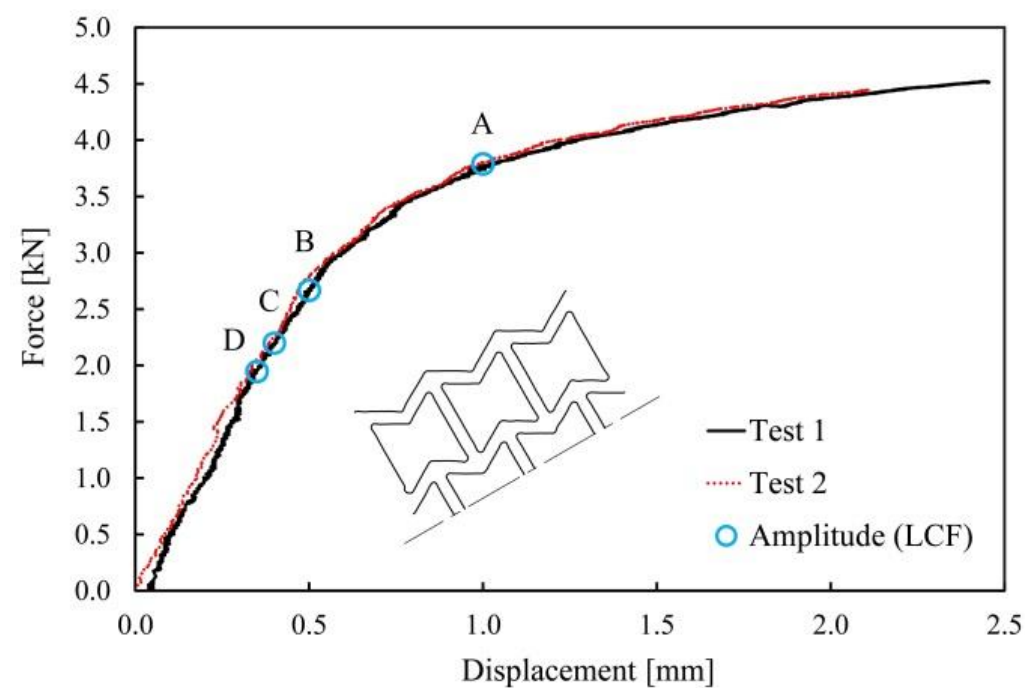

(B) Auxetic cellular specimen

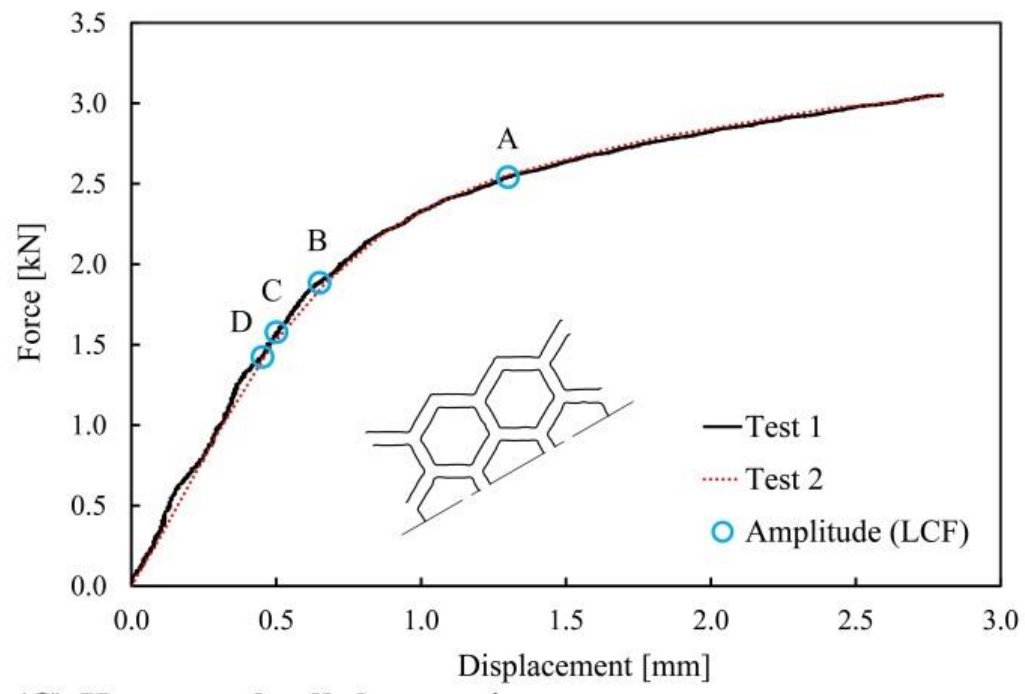

(C) Hexagonal cellular specimen

Fig. 3. Force-displacement diagrams of the static tensile tests: (A) auxetic-chiral structure, (B) auxetic structure and (C) hexagonal honeycomb structure 


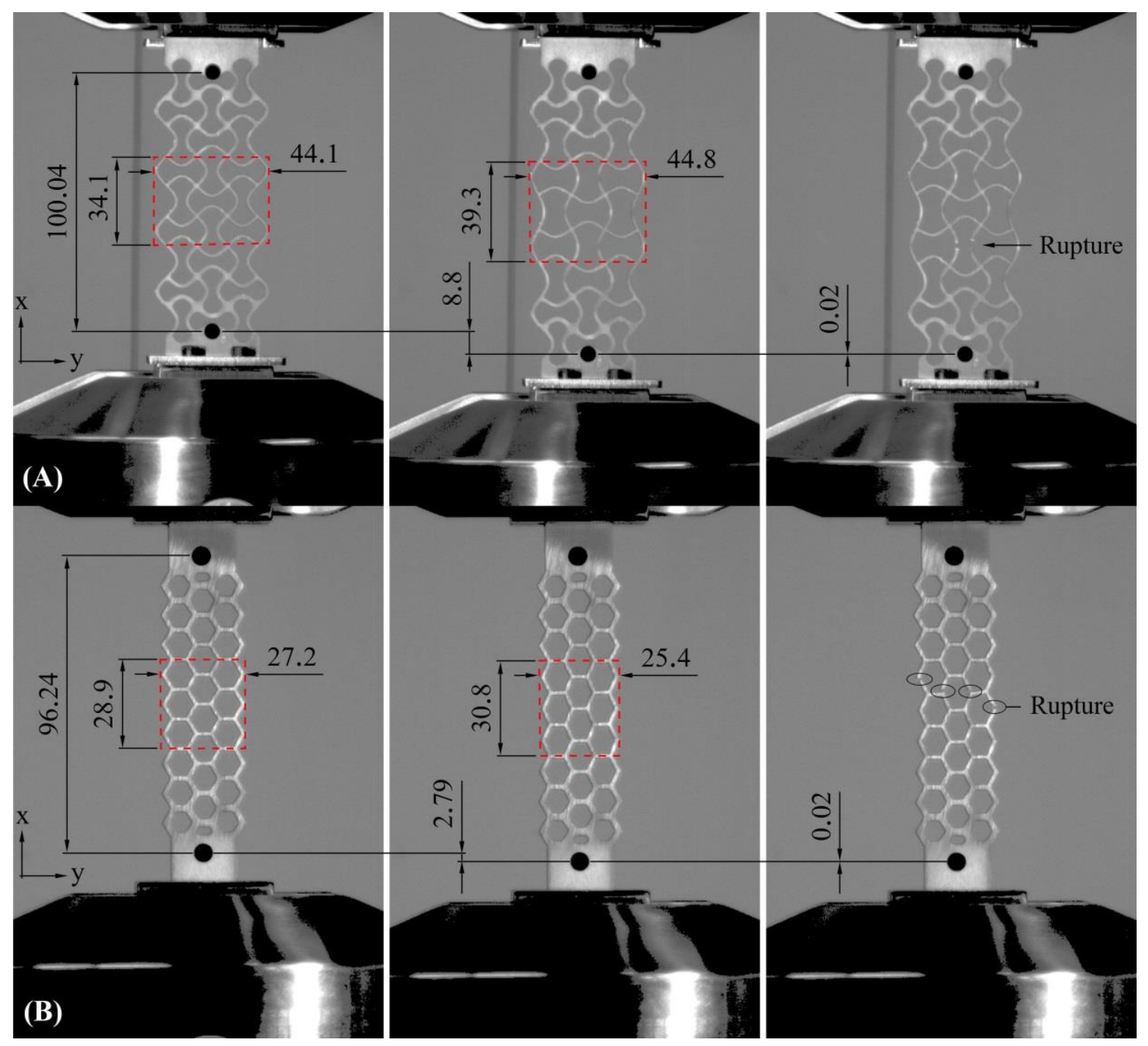

Fig. 4. Video-extensometer images for tensile tests of: (A) auxetic-chiral structure and (B) hexagonal structure

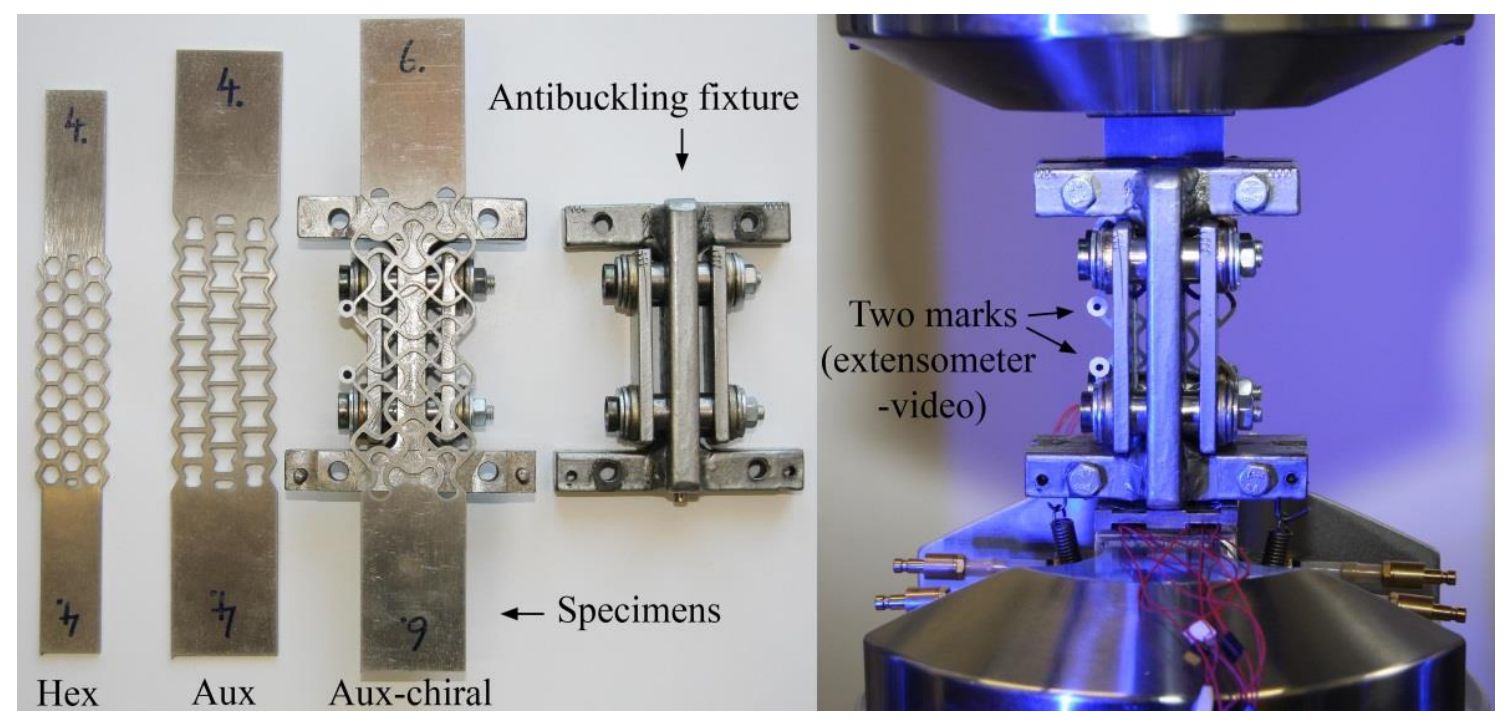

Fig 5. Experimental arrangement for low-cycle fatigue experiments of cellular structures 


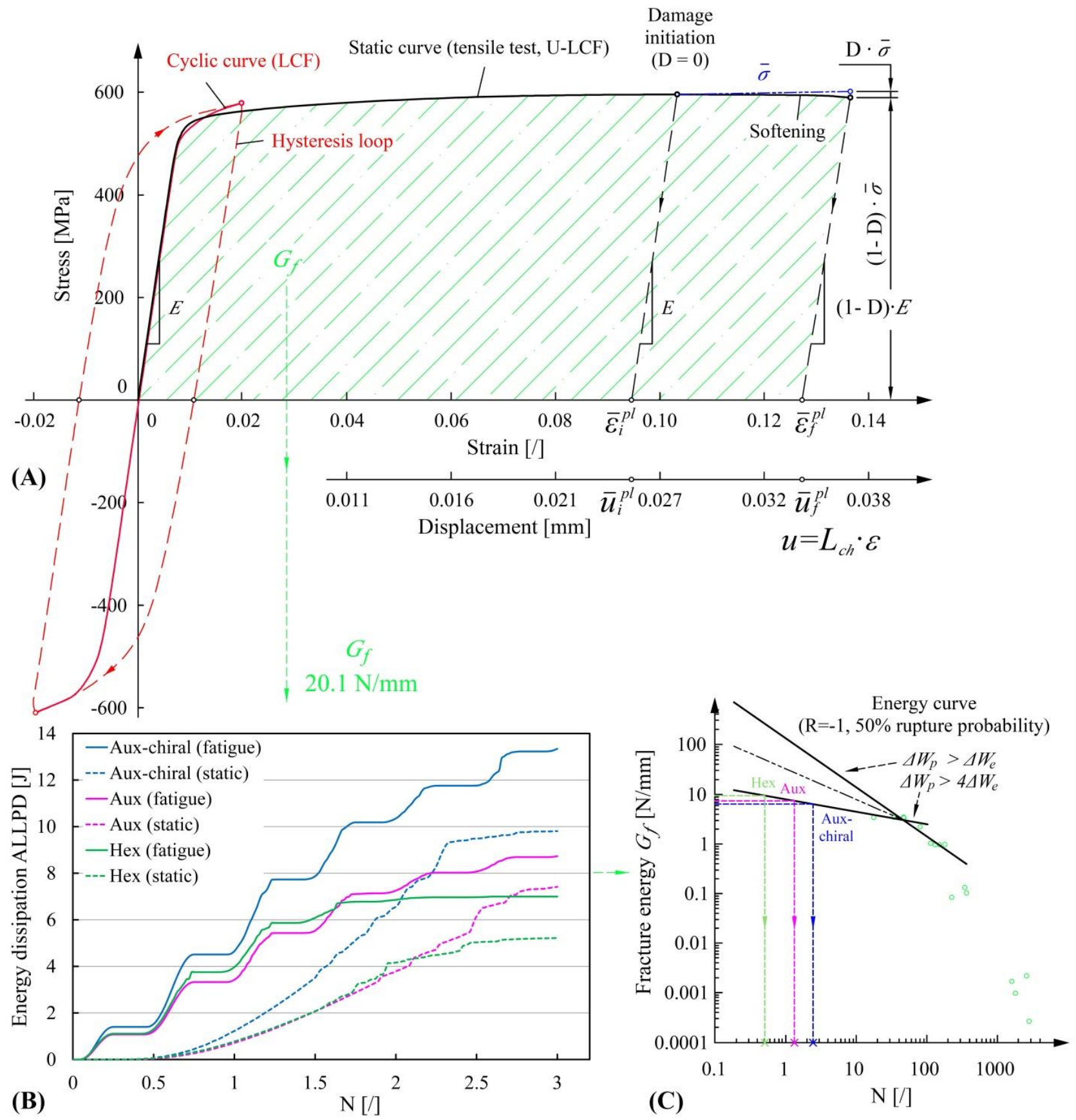

Fig. 6. Elastic-plastic response of the base material Al7075-T651 with an analysis of the progressive damage 

(A) Auxetic-chiral
(B) Auxetic
(C) Hexagonal

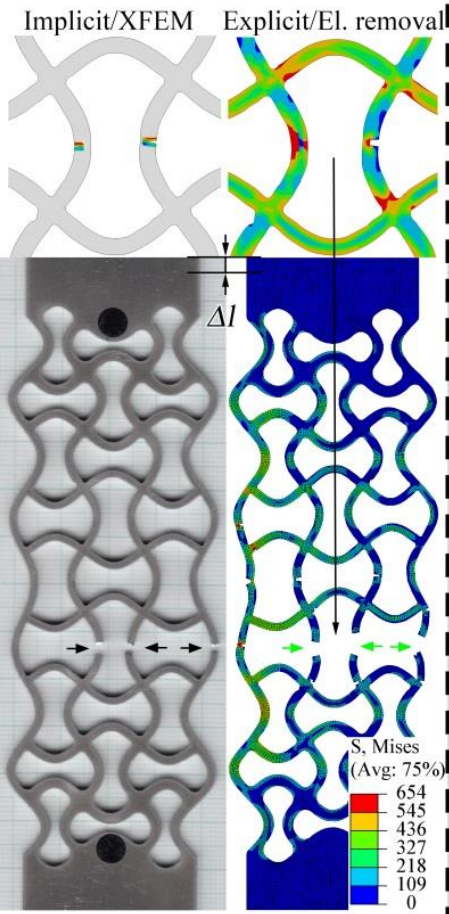

Experiment

$\Delta I=10.27^{\mathrm{b}}\left(8.8^{\mathrm{a}}\right)$

$\Delta l=9.1$

Implicit/XFEM

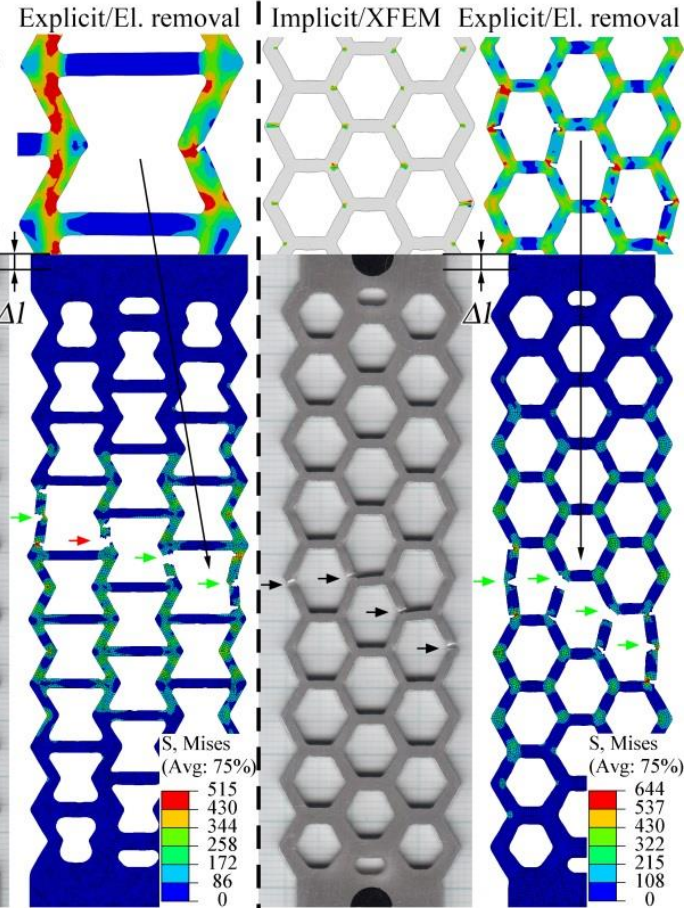

Experiment

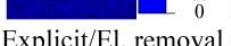

Experiment Explicit/El. removal $\Delta l=2.5 \quad$ I $\Delta l=2.8^{\mathrm{b}}\left(2.79^{\mathrm{a}}\right)$

$\Delta l=2.5$

Fig. 7. A comparison of experimental (left) and numerical (right) results of tensile tests; initial cracks obtained with different FE methods are presented above; (a-test 1, b-test 2)

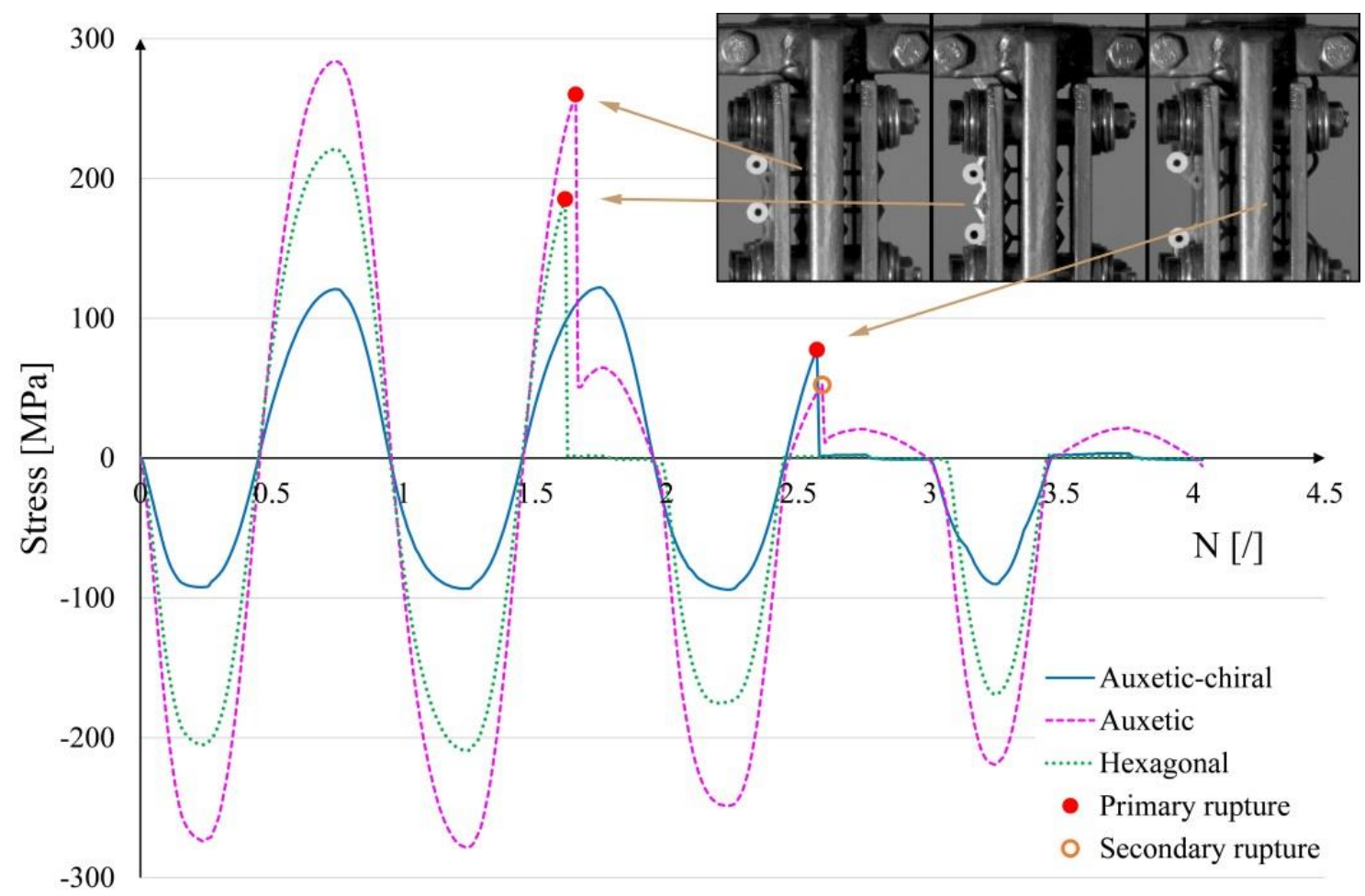

Fig. 8. Results of low-cycle fatigue experiments at the highest loading levels 

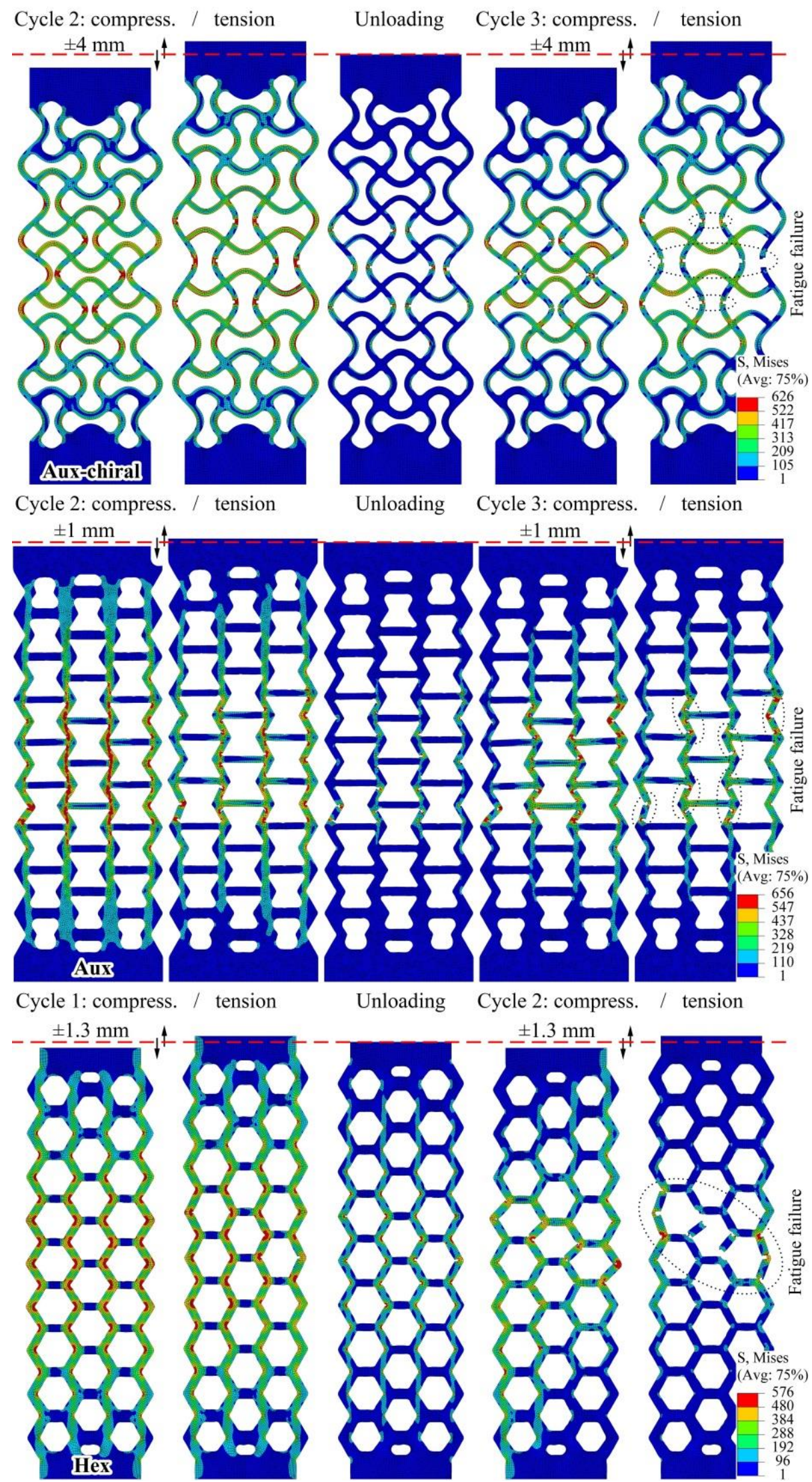

Fig. 9. Results of ultra-low cycle fatigue simulations using the damage evolution method combined with element 



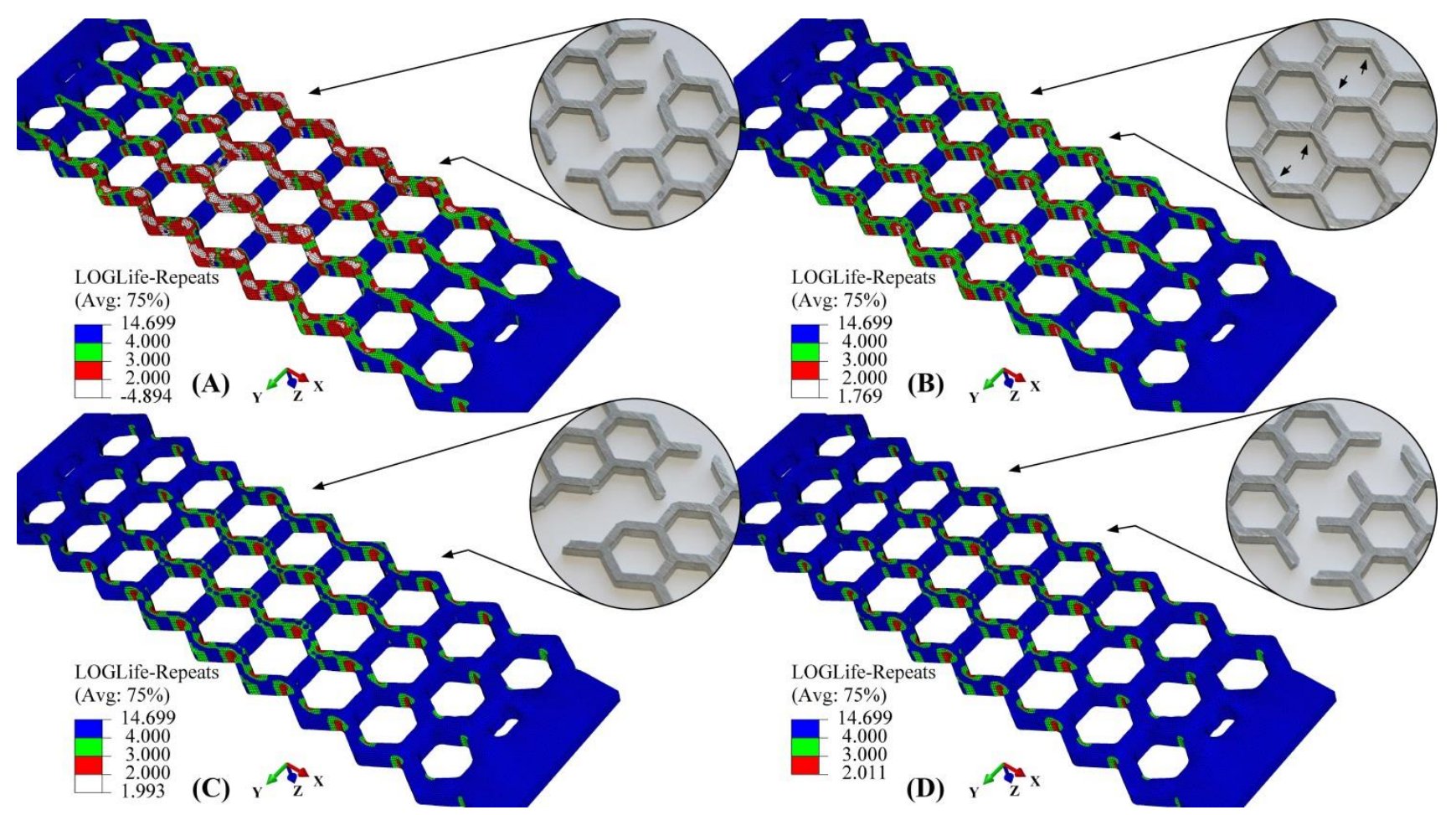

Fig. 12. Predicted logarithmic fatigue-life with the Brown-Miller (Morrow) model for the hexagonal structure for the four loading levels: (A) $\Delta l= \pm 1.3 \mathrm{~mm}$; (B) $\Delta l= \pm 0.65 \mathrm{~mm}$; (C) $\Delta l= \pm 0.5 \mathrm{~mm}$; (D) $\Delta l= \pm 0.45 \mathrm{~mm}$

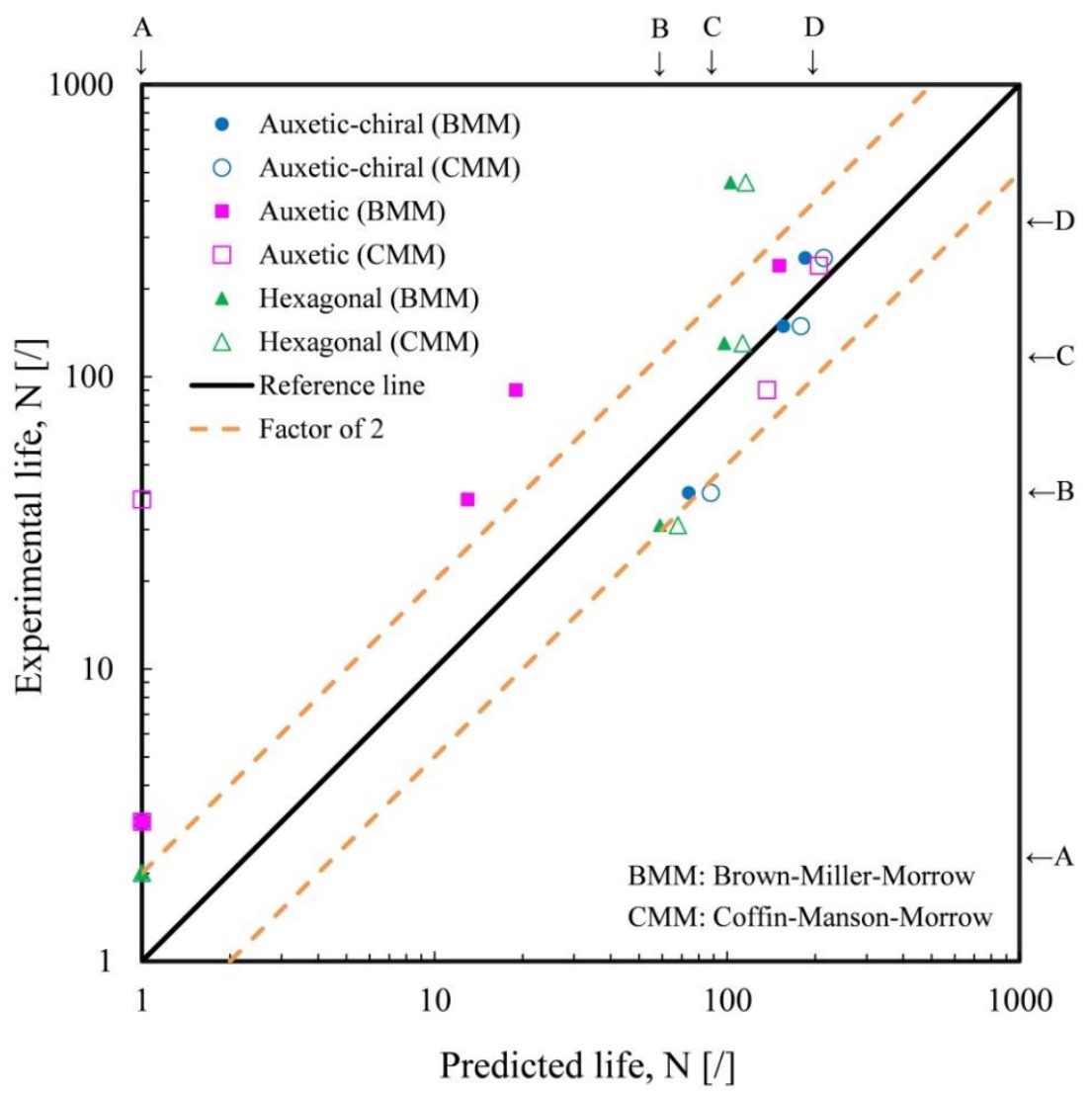

Fig. 13. Comparison of experimentally determined and numerically predicted fatigue lives of the cellular structures 